\title{
Opinião
}

\section{METODOLOGIAS PEDAGÓGICAS NA CONSTRUÇÃO DO CONHECIMENTO: UMA REFLEXÃO}

José Claudiano Xavier Ferreira (1) Kátissa Galgania Feitosa Coutinho Rodrigues (2)

Rafaelle Gleice dos Santos (3)

Sidney Medeiros de Oliveira (4)

\section{Resumo}

O presente estudo discorre sobre as práticas dos docentes universitários, apresentando como alternativas a um melhor resultado no aprendizado, a apropriação criativa de novas metodologias didáticas, incluindo-se aí, a apropriação e domínio dos novos aparatos tecnológicos como recurso auxiliar. Também revela o papel da interação e da criatividade como fundamentais para uma eficácia docente. Conclui pela necessidade de uma novas reflexões, no sentido de beneficiar a práxis pedagógica e suas ações, à partir da criação de novas formas didáticas e metodológicas de promoção do processo ensino-aprendizagem, conjuntamente com os alunos.

Palavras-chave: Metodologias pedagógicas, Construção do conhecimento, Ensino superior

\section{Introdução}

A educação e seus métodos sempre foram alvos de discussões e reflexões, o que implicou na sua melhoria em diversos aspectos e a consequente valorização do contexto escolar pelos discentes. Segundo Gadotti (2000), a educação, enraizada na sociedade de 
classes escravista da Idade Antiga, era destinada a poucos. Uma educação tradicional que declinou à partir do movimento renascentista, mas que sobrevive até hoje. Uma nova forma de fazer educação, surgiu nesses últimos dois séculos e trouxe consigo numerosas conquistas, sobretudo no campo das ciências da educação e das metodologias de ensino. O conceito de "aprender fazendo" de John Dewey e as técnicas Freinet, por exemplo, são aquisições definitivas na história da pedagogia. Tanto a concepção tradicional de educação quanto a nova, amplamente consolidadas, terão um lugar garantido na educação do futuro.

As inúmeras transformações sociais, que implicaram um amplo processo de desenvolvimento da escola, se apresenta como um dos aspectos relevantes a serem discutidos na sociedade, pois é nela que são promovidas as mais importantes formulações teóricas sobre o desenvolvimento cultural e social. A pesquisa educacional tem tomado lugar central na busca de perspectivas que possibilitem uma nova prática educacional, envolvendo principalmente os agentes que conduzem o ambiente escolar. A ideia é transformar o ensino em parte integrante ou principal, na motivação dessas transformações.

As modificações sofridas por nossa sociedade, principalmente em termos de avanços tecnológicos e de comunicações, aprimoraram nosso modo de pensar, que tornou-se menos autoritário e menos regrado. Dessa forma, os agentes educacionais e a escola, vêm vivenciando um processo de adaptação que tem refletido principalmente nas ações de seus alunos e na materialização destas, no contexto acadêmico. Fato que tem se tornado ponto de dificuldade e insegurança entre professores e agentes escolares, configurando uma forma de comprometimento do processo ensino-aprendizagem. Sobre isso, Gadotti (2000, p.6) afirma que,

Neste começo de um novo milênio, a educação apresenta- se numa dupla encruzilhada: de um lado, o desempenho do sistema escolar não tem dado conta da universalização da educação básica de qualidade; de outro, as novas matrizes teóricas não apresentam ainda a consistência global necessária para indicar caminhos realmente seguros numa época de profundas e rápidas transformações.

Nesta perspectiva, o presente estudo tem por finalidade discutir assuntos pertinentes a metodologias e pedagogias voltadas ao ensino superior no que diz respeito a criatividade, interatividade e troca de saberes entre docentes e discentes. Ressaltando uma maior flexibilidade por parte do educador para um melhor aproveitamento das competências e habilidades de cada aluno, observando-se a realidade cultural, educacional e social. 
Assim, o professor precisa buscar desenvolver e utilizar-se de metodologias e recursos didáticos, de maneira criativa, visando estimular a construção, produção e desenvolvimento do conhecimento dos seus alunos, aproveitando-se as experiências pré- existentes dos mesmos.

Dentro desde novo contexto cultural, os saberes, certamente, irão se diversificando cada vez mais, cabendo ao educador, o papel de mediador desses elementos, abrindo espaço para novas ideias. Afinal, ambos fazem parte, através da interação mútua, do processo ensinoaprendizagem.

\section{Metodologias pedagógicas e a construção do conhecimento}

É visível se notar que, o desenvolvimento acelerado, onde as informações se autoatualizam em frações de segundos, ocasiona de certa forma, um desgaste dos profissionais, além de comprometimento as ações voltadas para o aprimoramento do ensino. Muitas vezes, tem-se a sensação de que a sala de aula parece um ambiente de pouca relevância para a consolidação do conhecimento, tamanha a carência de acompanhar toda a tecnologia gerada, sem que as partes interessadas possam ter acesso imediato. Esta situação, tende a tornar a vivência social um requisito primordial para a busca de aprendizado.

Sobre isso, Hamze (2004, p.1) afirma que,

\footnotetext{
Como educadores não devemos identificar o termo informação como conhecimento, pois, embora andem juntos, não são palavras sinônimas. Informações são fatos, expressão, opinião, que chegam as pessoas por ilimitados meios sem que se saiba os efeitos que acarretam. Conhecimento é a compreensão da procedência da informação, da sua dinâmica própria, e das conseqüências que dela advém, exigindo para isso, um certo grau de racionalidade. A apropriação do conhecimento, é feita através da construção de conceitos, que possibilitam a leitura critica da informação, processo necessário para absorção da liberdade e autonomia mental.
}

Dessa forma, para se construir o conhecimento, o professor precisa não apenas conhecer o conteúdo, mas ter habilidades e criatividade para moldar as ideias expostas pelos alunos. No seu campo de atuação deve ter um conjunto de outros saberes pedagógicos, de 
forma a tornar o processo de ensino não estático e minimizar a passividade por parte dos discentes.

A metodologia aplicada precisa favorecer o aprendizado através da reflexão, estimulando a criação de novas práticas, tais como: aceitação das indagações dos alunos; flexibilização das formas didáticas; apropriação, conhecimento e utilização das tecnologias da informação disponíveis; formação de parcerias com os discentes, incentivando a pesquisa, dentre outras ações.

Dentro deste raciocínio Dowbor (1998, p. 259) nos orienta,

...será preciso trabalhar em dois tempos: o tempo do passado e o tempo do futuro. Fazer tudo hoje para superar as condições do atraso e, ao mesmo tempo, criar as condições para aproveitar amanhã as possibilidades das novas tecnologias.

De acordo com o autor, no meio social atual é inadmissível um professor com uma postura absolutista e centralizadora no processo acadêmico, que não permita a troca de conhecimentos entre docentes e discentes. Essa postura compromete o aprendizado em ambas as partes, uma vez que a interação das experiências favorece o insight e amplia a temática, além de promover a geração de novos conhecimentos.

Segundo Lima (2010 apud Freire et all 1999), é preocupante quando nos referimos à prática da docência de forma absolutista, seja do ensino primário, fundamental, médio ou superior, onde a autoridade de alguns professores, em sala de aula ou em aulas práticas, faz com que os mesmos despejam os conteúdos, sem uma real preocupação com a aprendizagem dos seus alunos.

Isso significa dizer que o docente deverá ter autonomia, e não autoridade nociva, que tolhe oportunidades. Este tipo de autoridade é dita nociva, por não levar em conta as experiências e realidade social dos educandos. O conhecimento da realidade social, cultural e econômica dos alunos, ajuda o professor a trazer conteúdos mais adaptados, certamente obtendo mais condição de ter êxito nos seus propósitos educacionais.

\section{A Criatividade docente para a eficácia do ensino-aprendizagem}

No modelo tradicional a criatividade era reprimida. As aulas tinham um arcabouço rígido em forma expositiva, onde o professor expunha o conteúdo, em geral, não permitindo 
uma interação aluno-professor. As novas ideias eram limitadas apenas ao seu conhecimento, pois o professor era o centro das atenções e os alunos apenas meros espectadores.

Segundo Dowbor (1998, p.259),

\begin{abstract}
A escola precisa deixar a postura "lecionadora" para ser "gestora do conhecimento". A autora prossegue dizendo que, a educação, na atualidade, tem a possibilidade de ser determinante sobre o desenvolvimento. A educação tornou-se estratégica para o desenvolvimento, mas, para isso, não basta "modernizá-la" como querem alguns. Será preciso transformá-la profundamente.
\end{abstract}

Nos dias de hoje essa forma de apresentação dos conteúdos (somente expositiva) está ultrapassada, uma vez que deve- se estimular o raciocínio dos alunos expondo a matéria de forma criativa e interessante. Cabe aos expectadores formar ideias e tirar suas próprias conclusões, sendo o professor um mediador deste processo.

A criatividade do professor vai desde a disposição dos alunos em sala de aula, as dinâmicas a serem utilizadas, as argumentações, discussões, projetos, interações com o grupo, até as mudanças apresentadas nesse processo. O docente deve se utilizar de todos os artifícios e de toda a sua criatividade, para que os discentes consigam entender o que está sendo explicado e, dessa forma, cheguem a uma conclusão desejável, seja esta já esperada pelo professor, ou não.

Segundo Lima (2012) apud Freire (1999), dentro de uma instituição precisa existir a epistemologia da crítica, ou seja, fazer com que o aprendiz possa criticar pensar e refletir fazendo com que tenha mais vontade de buscar.

Os mesmos assuntos que estudamos no passado de forma expositiva e/ou decorativa, agora devem ser explicados, através de recursos que provoquem o entendimento e a discussão por parte dos "aprendizes". Hoje o educador conta com facilidades que podem ajudar na transmissão do conhecimento, como por exemplo: o data-show, o notebook, a lousa digital. Existem ainda outros recursos que podem ser utilizados, tais como a internet em salas de multimeios e diversas metodologias associadas, como é o caso do trabalho colaborativo - uma forma de difusão do saber através do uso de programas de computador específicos.

Utilizando sua criatividade, o professor pode se utilizar de outros artifícios não tecnológicos como por exemplo: mímicas, artes cênicas, conteúdos de áudio, reflexões à partir de filmes, dentre outros que o ajudem a facilitar o entendimento dos alunos sob sua responsabilidade.

Beherens (1991, P.12) considera que, 
Os novos tempos exigem um padrão educacional que esteja voltado para o desenvolvimento de um conjunto de competências e de habilidades essenciais, a fim de que os alunos possam fundamentalmente compreender e refletir sobre a realidade, participando e agindo no contexto de uma sociedade comprometida com o futuro.

Assim, vemos que o formato de ensino no Brasil estava desatualizado, com um tipo tecnicista de se transmissão dos conteúdos, ou seja, não havia a preocupação de como o aprendiz estava recebendo as informações. Os novos tempos e as inovações tecnológicas impulsionaram transformação no que diz respeito a didática, de forma a promover uma maior preocupação do docente com relação a sua práxis. Para isso foi necessária uma mudança e uma quebra de paradigmas, já que desde muito tempo, o ensino era repassado de forma que o professor era o senhor do saber e, o aluno, apenas um expectador. Um mero aprendiz.

Segundo Gadotti (2000), na sociedade da informação, a escola deve servir de bússola para navegar nesse mar do conhecimento, superando a visão utilitarista de só oferecer informações "úteis" para a competitividade, para obter resultados. Deve oferecer uma formação geral na direção de uma educação integral. O que significa servir de bússola? Significa orientar criticamente, sobretudo as crianças e jovens, na busca de uma informação que os faça crescer e não embrutecer.

Toda mudança implica em riscos. Com essa nova modalidade de ensino, o docente passou a perceber que os alunos também trazem uma boa bagagem de experiências e conteúdos, capazes de gerar novas ideias, conclusões e opiniões. Neste modelo, o professor passa também a condição de aprendiz, havendo uma troca de papéis em determinados momentos.

Segundo Cunha (1998, p. 23), atualmente a maneira mais adequada de se transmitir os conteúdos é através de uma interação entre professor-aluno. De acordo com o autor,

\footnotetext{
Professores universitários envolvidos com a inovação na universidade têm uma concepção de conhecimento que envolve flexibilidade e movimento, entendem o conhecimento como construção, incentivam a dúvida, valorizam o erro e trabalham com base nele. A provisoriedade, a multiplicidade e o momento permeiam o cotidiano.
}

Ainda em relação a este assunto, Machado (1994) nos orienta que, compreender é apreender o significado de um objeto ou de um acontecimento; é vê-lo em suas relações com outros objetos ou acontecimentos; os significados constituem, pois, feixes de relações que, por sua vez se 
entretecem, se articulam em teias, em redes, construídas socialmente e individualmente, e em permanente estado de atualização.

Sendo assim, a compreensão de atividades criativas em sala significam novos horizontes a serem seguidos neste período de mudanças educacionais no Brasil. E, o crescimento do ensino superior, sendo aproveitado por cada profissional uma prática pedagógica da responsabilidade pelo organismo dos conhecimentos e desta nova sociedade de redes e de práticas.

\section{A transmissão do conhecimento à partir da lógica da interdisciplinaridade}

A Educação Superior no Brasil funda-se, num modelo linear e fragmentador do conhecimento. Nessa perspectiva, aderente a uma concepção que se encontra presente, e às vezes dominante, em todos os ramos do pensamento. O conhecimento é apresentado como um bloco passível de ser dividido em segmentos.

A prática pedagogia atual, tradicional, disciplinar, favorece a configuração da fragmentação de conhecimentos. Dessa forma, ressalta-se a necessidade de se introduzir práticas de ensino inovadoras, no sentido de reverter esse problema. Nessa perspectiva, é bom salientar a prática da interdisciplinaridade como a melhor forma de diminuir a dissociação entre a realidade da escola e o seu objetivo. No caso, de formar homens plenos, não sendo ignorados os diversos obstáculos emergentes. Utiliza-se a abordagem qualitativa para a pesquisa, na qual buscamos investigar, por intermédio da análise de textos de autores, a prática da interdisciplinaridade, que se fundamenta no ensino por projeto, priorizando uma prática pertinente e adequada à construção de conhecimentos globais e, portanto, significativos.

No campo científico, a interdisciplinaridade equivale à necessidade de superar a visão fragmentada da produção de conhecimento e, de articular as inúmeras partes que compõem os conhecimentos da humanidade. Busca-se estabelecer o sentido de unidade, de um todo, na diversidade. Mediante uma visão de conjunto, permite-se ao homem tornar significativas as informações desarticuladas que o mesmo possa vir a receber.

A divisão do saber em compartimentos parece ter surgido em decorrência da necessidade de especialização dos profissionais no contexto da industrialização da sociedade. A escola, paulatinamente, foi sendo influenciada pelo processo de industrialização, no qual, cada indivíduo passou a exercer uma função específica no processo de produção material. 
Porém, hoje, se sente a necessidade da unificação do conhecimento. Assim, cresce o interesse pelo conhecimento unificado e, portanto, pelas pesquisas interdisciplinares, por parte dos cientistas, filósofos e planejadores.

\section{Construção do conhecimento cotidiano à partir da pesquisa científica}

O conhecimento não se restringe apenas em informações que são transmitidas de um ser para o outro, porém pode ser construído de acordo com a cultura de cada indivíduo. Assim, dentro da ambiência de sala de aula, o mesmo pode ser adquirido, compartilhado, discutido e ampliado. É necessário compreender também como se dá a relação entre a pesquisa científica como produção do conhecimento, com a prática docente em sala de aula.

Deste modo, a construção do conhecimento está interligada tanto a princípios éticos, como as questões sociais e educacionais. Ora se aquele aluno é conhecedor de tal assunto com profundidade, ou seja, baseado nas suas leituras e vivências cotidianas, é a partir dessa vivência que se tornará bem proveitosa para a difusão de sua pesquisa científica.

Sabendo que várias instituições dão suporte às pesquisas científicas, cabe às mesmas investirem nos seus pesquisadores e, proporcionar aos mesmos o acesso a recursos que facilitem o desenvolvimento de seus estudos.

A pesquisa científica é uma metodologia importante e capaz de transformar a realidade. Daí a necessidade do professor, junto com os alunos, se apropriarem deste rico instrumento, e fazer utilização em sala de aula, nas mais diversas áreas do saber. Mas para que isso aconteça de fato, é imprescindível ter um conhecimento proveitoso e avançado nos assuntos pretendidos e incentivos em sala de aula, pois ainda hoje, a universidade, lamentavelmente, se depara com discentes que frequentam a Universidade apenas para adquirirem um título de ensino superior.

A partir dessa perspectiva, a aprendizagem em sala de aula se torna cada vez mais importante, pois é preciso que o aprendiz ponha em prática os seus questionamentos pessoais, aliados às teorias apreendidas em sala de aula, para assim, poder instrumentalizar-se para a pesquisa.

É importante ressaltar a relevância que a pesquisa acadêmica tem na construção do saber e, no ambiente do ensino. De acordo com Lima (2010) apud Laville e Dione (1999, p. 21), 
[...] a escola tem por missão ensinar, além disso, o modo de construção do saber, de modo que os estudantes também aprendam os princípios de sua validade e se tornem progressivamente capazes de julgar o saber oferecido e, até, eventualmente, de preferir outro ou construir, por si mesmos, um saber diferente.

O conhecimento só é construído através de discussões e da reflexão crítica, do saber já existente. A escola como academia tem como princípios básicos, desenvolver e estimular a curiosidade científica e a criticidade dos assuntos abordados nos encontros. Nessa dimensão, insere-se o professor como facilitador do processo de ensino-aprendizagem. $\mathrm{O}$ docente tem o papel de principal agente motivador à pesquisa, uma vez que ele é quem primeiro apresenta novos conhecimentos aos discentes.

Gadotti (2000, p. 8), sobre o assunto, nos orienta que,

Seja qual for à perspectiva que a educação contemporânea tomar, uma educação voltada para o futuro será sempre uma educação contestadora, superadora dos limites impostos pelo Estado e pelo mercado, portanto, uma educação muito mais voltada para a transformação social do que para a transmissão cultural.

A prática educativa não deve ser encarada apenas como acertos, deve ser repensada na visão da não transferência de estruturas pré- determinadas pelo sistema, ao qual, estão inseridos os professores. O erro e a dúvida abrem espaço para formação consciente dos sujeitos enquanto aprendizes, independentemente de ser professor ou aluno comungarão da construção de um novo saber. Segundo Magalhães, et al.,( 2005, p.2) apud Freire (1999), formar é muito mais que puramente treinar o educando no desempenho de destrezas, e continua,

É na inconclusão do ser, que se sabe como tal, que se funda a educação como processo permanente. Mulheres e homens se tornaram educáveis na medida em que se reconheceram inacabados. Não foi a educação que fez mulheres e homens educáveis, mas a consciência de sua inconclusão é que gerou sua educabilidade. É também na inconclusão de que nos tornamos conscientes e que nos inserta no movimento permanente de procura que se alicerça a esperança. "Não sou esperançoso", disse certa vez, por pura teimosia, mas por exigência ontológica.

Se o ser humano se torna acabado, se acaba por si só, por que a educação é gerada pela vontade de aprender e consertar erros. Tudo isso, diante de normas que podem ser mudadas a 
cada época e diante de cada contexto. O professor precisa interagir na busca de experiências que ofereçam aos alunos oportunidade de reflexão.

Para acertar é preciso ter aprendido, e para aprender é preciso ter buscado diante dos erros novas interlocuções e desdobramentos para cada situação conflitante e desafiadora.

\section{Conclusões}

A educação parece passar por um processo de amadurecimento, em que o regime tradicional e tecnicista está perdendo espaço para uma metodologia mais atual e reflexiva. $\mathrm{O}$ onde antes os discentes eram meros coadjuvantes, agora se tornam mais participativos no seu processo de construção do conhecimento. As novas metodologias, surgidas em decorrência do processo de desenvolvimento tecnológico e das comunicações, proporcionou uma maior interação entre professor-aluno, de forma que estes últimos saem da condição de expectadores para construtores de sua história acadêmica.

Pelo exposto, vimos que, a prática pedagógica dos educadores no momento atual, bem como a condução do processo ensino-aprendizagem na sociedade contemporânea, precisa ter como premissa básica, a necessidade de uma reformulação pedagógica que priorize uma prática formadora para o desenvolvimento. Nesse contexto, a escola deixa de ser vista como uma obrigação a ser cumprida pelo aluno, e se torna uma fonte de efetivação de seu conhecimento intelectual e de prazer pelo fazer e pelo conhecer. Certamente, isso motivará muito mais os atores educacionais (professores e alunos) a participarem do processo de desenvolvimento social, não como mero receptor ou promotor de informações, mas como idealizador de práticas que favoreçam esse processo.

Assim, faz-se necessária uma nova reflexão no processo educativo, onde o docente passe a vivenciar essas transformações de forma a beneficiar sua práxis pedagógica e suas ações, buscando construir novas formas didáticas e metodológicas de promoção do processo ensino-aprendizagem, conjuntamente com seu aluno.

\section{Referências}

BEHRENS, M. A., 1999. A prática pedagógica e o desafio do paradigma emergente. Revista Brasileira de Estudos Pedagógicos, 80:383-403. 
CUNHA, M. I. O Professor universitário na transição de paradigmas. Araraquara: JM Editora, 1998.

DOWBOR, L. A reprodução Social. São Paulo: Vozes, 1998.

FREIRE, P. Pedagogia da autonomia: saberes necessários à prática educativa. Rio de Janeiro: Paz e Terra, 1999.

GADOTTI, M. Perspectivas atuais da educação. Porto Alegre: Ed. Artes Médicas, 2000.

LAVILLE, C.; DIONNE, J. A construção do saber: manual de metodologia da pesquisa em ciências humanas. Porto Alegre: Artes Médicas, 1999.

LIMA, M.L. Apostila do módulo de História da Educação Superior no Brasil. Crato: Faculdades Integradas de Patos, 2012.

MACHADO, J. N. Conhecimento como rede: a metáfora como paradigma e como processo. São Paulo: Instituto de Estudos Avançados, 1994.

MAGAlHÃES, A.G. ; ROMUALDO, A. S.; LIMA, M.C.G.[et al]. A formação de professores para

a diversidade na perspectiva de Paulo Freire . V Colóquio Internacional Paulo Freire.- Recife, 19 a $22 . s e t .2005$, p.2- 4 .

Sobre os autores:

1. José Claudiano Xavier Ferreira é graduado em Licenciatura em Educação Física pela Universidade Vale do Acaraú - UVA. Especializando em Prática Docente do Ensino Superior pela Faculdades Integradas de Patos - FIP. E-mail: jcim@bol.com.br;

2. Kátissa Galgania Feitosa Coutinho Rodrigues é graduada em Biblioteconomia pela Universidade Federal do Ceará; Graduanda em Psicologia pela Faculdade Doutor Leão Sampaio e Especializanda em Prática Docente do Ensino Superior pela Faculdades Integradas de Patos - FIP. E-mail: katissagalgania@yahoo.com.br;

3. Rafaelle Gleice dos Santos.. é graduada em Biblioteconomia pela Universidade Federal do Ceará, Licenciada em Geografia pela Universidade Regional do Cariri e, Especializanda em Prática Docente do Ensino Superior pela Faculdades Integradas de Patos - FIP. E-mail: rafaelleufc @ yahoo.com.br

4. Sidney Medeiros de Oliveira.. é graduado em Licenciatura em Educação Física pela Universidade Federal de Pernambuco - UFPE. Especializando em Prática Docente do Ensino Superior pela Faculdades Integradas de Patos - FIP. E-mail: sidneymeolli@gmail.com.

Como citar este artigo (Formato ISO):

FERREIRA, J.C.X.; RODRIGUES, K.G.F.; SANTOS, R.G.S.; OLIVEIRA, S.M.. Metodologias Pedagógicas na Construção do Conhecimento: Uma Reflexão. Id on Line Revista de Psicologia, Fevereiro de 2012, vol.1, n.16, p.17-27. ISSN 1981-1189. 